\title{
Isolation, screening and characterization of Streptomyces espinosus from rhizospheric soil for Genistein production
}

\author{
${ }^{1}$ Umesh Luthra*, ${ }^{2}$ Harish Kumar, ${ }^{3}$ Nishtha K. Singh, ${ }^{4}$ Amitabh Chaturvedi, \\ ${ }^{5}$ Vandana Gupte, ${ }^{6}$ Sneha Khadpekar, ${ }^{7}$ Brajesh Kumar Sharma, ${ }^{8}$ Laki Magar and \\ ${ }^{9}$ R.R. Patil \\ 1,2,3,4,5,6,7,8,9 Ipca Laboratories Ltd., Biotech R\&D, Kandivali, Mumbai- 400067, Maharashtra, India \\ Corresponding Author: umeshluthra@gmail.com
}

\begin{abstract}
Genistein is a phytoestrogen and belongs to the category of isoflavones. Most of the isoflavones in plants are present in a glycosylated form. The unglycosylated aglycones can be obtained through various means such as treatment with the enzyme $\beta$-glucosidase, acid treatment of soybeans followed by solvent extraction, or by chemical synthesis. Acid treatment is a harsh method as concentrated inorganic acids are used. Both enzyme treatment and chemical synthesis are costly. Chemically synthesized genistein or genistein extracted from soyabean currently can cost upto $\$ 5,000$ a gram. A more economical process consisting of fermentation for in situ production of $\beta$-glucosidase to isolate genistein. They are naturally occurring chemical constituents that may interact with estrogen receptors to produce weak estrogenic or anti-estrogenic effects. Because of potential clinical use of genistein as chemopreventive and/or chemotherapeutic agent it is highly important to produce this isoflavone. The present invention provides an alternate process for the large scale production of genistein by Streptomyces espinosus. Fifty three filamentous bacterial isolates were isolated from total of ten soil sample collected from different sites of Mumbai out of which one colony was found to produce Genistein which could be used for further studies and it was termed as Z. On the basis of morphological, physiological, biochemical and molecular characterization the isolated strain $Z$ was confirmed as Streptomyces espinosus and the metabolite produced by Streptomyces espinosus was characterized by HPLC, Mass, NMR and IR spectroscopy and confirmed as genistein.
\end{abstract}

Abbreviation: Streptomyces espinosus, Genistein, NMR, HPLC

\section{Introduction}

Genistein was first isolated in 1899. It is one of the several known isoflavones. The main sources of Genistein are soybeans. It acts as a phytoestrogen, antioxidant \& anticancer agent. The Genistein which we have isolated is produced by Steptomyces espinoses, which has not been reported so far. Genistein is a phytoestrogen (estrogen-like chemical compound present in plants) that is derived from certain plant precursors by human metabolism. They are naturally occurring chemical constituents that may interact with estrogen receptors to produce weak estrogenic or anti-estrogenic effects. They are composed of a wide group of non-steroidal compounds similar in structure and function to human estrogens (Leclerq G. and Heuson J.C., 1979). A conspicuous feature of the chemical structure of phytoestrogens is the presence of a phenolic ring that, with few exceptions, is a prerequisite for binding to the estrogen receptor. For this reason, phytoestrogens can act as weak estrogen agonists, partial agonists, or as antagonists to endogenous estrogens (such as estradiol) and xenoestrogens (including phytoestrogens) with estrogen receptors in both animals and humans. Therefore, working as estrogen, genistein mimics phytoestrogens. It may either have same effects as estrogen or block estrogen's effects. There are three major classes of plant chemical compounds that have estrogen-like actions in the body. They are lignans (enterolactone, enterodiol), isoflavones (genistein, daidzein, biochanin A), and coumestans. The two major chemical classes of phytoestrogens found in people's diets are lignans (enterodiol and enterolactone) and isoflavones (daidzein, genistein, and glycitein). Genistein is an isoflavone. Isoflavone are a class of flavonoids, natural products typically isolated in glycosylated form from plants. The aglycone is the biologically active form that has the most medicinal and commercial interest.

The glycosylated form of genistein is known as genistin. The preparation of genestein must include a step in which the core isoflavone structure (genistein) is separated from the glucose moiety. Genistin, which is found in soyabean, is converted to the biologically active form, genistein, through the action of a betaglucosidase enzyme. Genistein is reported to be an inhibitor of eukaryotic DNA topoisomerase (topo) I and II. Genistein is used as a chemopreventive agent in animal studies, is required for clinical trials as a dietary supplement; and likely has application as a chemotherapeutic agent when coupled to anti-tumour specific antibodies. Because of potential clinical use of genistein as chemopreventive and/or chemotherapeutic agent it is 
highly important to produce this isoflavone and some of its promising structural analogs in larger quantities and to reduce its price. Genistein is currently expensive. Chemically synthesized genistein or genistein extracted from soyabean currently can cost upto $\$ 5,000$ a gram.

Members of the genus Streptomyces are filamentous Gram-positive soil bacteria with a typical base composition of 72-75 mol\% G + C (Enquist \& Bradley, 1971; Piepersberg, 1993). Streptomyces undergo complex morphological differentiation including growth of substrate mycelia in the initial phase, followed by development of aerial mycelium and its subsequent conversion to spores (Piepersberg, 1993). Streptomyces possess extensive secondary metabolic pathways leading to the production of a wide array of bioactive compounds including commercially important substances such as antibiotics. The metabolic diversity of these indigenous soil micro-organisms has been widely exploited in industry and agriculture (Mehling A. et al., 1995).

The present invention provides an alternate process for the large scale production of genistein by Streptomyces espinosus, the organism that is used in the production of lincomycin. To best knowledge of authors and thorough literature search it is concluded that Genistein produced by Steptomyces espinosus is novel and not reported before.

\section{Isolation and Screening of Genistein producing Actinomycetes \\ II. Materials and Methods}

Soil samples were collected aseptically from different sites of Mumbai, India at a depth of 6-12 inches. Soil sample was dried in hot air oven at $50{ }^{\circ} \mathrm{C}$ for $1 \mathrm{hr}$ to minimize the amount of bacteria other than Actinomycetes (Williams et al., 1972; Arunachalam et al., 2010). Standard dilution plate technique was followed for the isolation of Actinomyctes (Kuster and Williams, 1964). 10 gm each of soil sample was added to $90 \mathrm{ml}$ distilled water in a $250 \mathrm{ml}$ Erlenmeyer flask under sterile condition and kept in rotary shaker (120rpm) at room temperature for $1 \mathrm{hr}$. Supernatant was collected and serially diluted to obtain $10^{-4}, 10^{-5}$ and $10^{-6}$ dilutions. Each dilution was plated on nutrient agar and Actinomycetes agar medium supplemented with Nalidixic acid. After inoculation of 7-9 days at $27 \pm 1^{\circ} \mathrm{C}$ the actinomycetes colonies were selected, counted and made into pure culture following single spore culture technique. The culture was maintained on yeast malt extract agar by periodic sub-culturing. The $\mathrm{pH}$ was adjusted to $7.2 \pm 0.1$ before autoclaving the medium at $121^{\circ} \mathrm{C}$ for $15 \mathrm{~min}$.

\section{Phenotypic characterization of isolated actinomycetes}

The isolated strain was morphologically and biochemically characterized according to Bergey's Manual of Determinative Bacteriology by Holt et al. (1994).

\section{DNA isolation for genotypic characterization}

Isolation and purification of DNA were carried out according to the method described in Sambrook and Russell, (2001). For the isolation of genomic DNA pure cultures were grown in YM broth till log phase was achieved. $1.5 \mathrm{ml}$ of bacterial culture was centrifuged for $10 \mathrm{~min}$ at $8,000 \mathrm{rpm}$ to get bacterial pellets. The supernatant was discarded and the cells were washed with $1 \mathrm{ml}$ cold TE buffer ( $\mathrm{pH}$ 8.0). $180 \mu \mathrm{l}$ lysis buffer and $2 \mu \mathrm{l}$ of RNase were added to the cell pellets. The cell pellets were resuspended by vortex and incubated at $37^{\circ} \mathrm{C}$ for $60 \mathrm{~min}$. Then $25 \mu \mathrm{l}$ proteinase $\mathrm{K}$ and $200 \mu \mathrm{l}$ AL buffer were added, mixed by vortex for few seconds and incubated at $56{ }^{\circ} \mathrm{C}$ for $30 \mathrm{~min}$. Homogenous mixture was essential for efficient lysis. Then $200 \mu 1$ of ethanol (96 $-100 \%$ ) was added to the lysate and mixed thoroughly by vortexing for $15 \mathrm{sec}$. The sample was added in the DNeasy mini spin column and centrifuged at $8000 \mathrm{rpm}$ for $1 \mathrm{~min}$. The flow was discarding through liquid and the spin column was placed in a new $2.0 \mathrm{ml}$ collection tube. $500 \mu \mathrm{l}$ of AW1 buffer was added to the spin column and centrifuged at 8,000 rpm for $1 \mathrm{~min}$ followed by addition of $500 \mu \mathrm{l}$ AW2 buffer and then centrifuged at 8,000 rpm for $3 \mathrm{~min}$. The DNA was eluted by adding $200 \mu \mathrm{l}$ of AE buffer directly into the column without spilling to the sides. It was incubated for $5 \mathrm{~min}$ at room temperature and centrifuged at 8,000 rpm for $1 \mathrm{~min}$. The eluted DNA was stored at $-20^{\circ} \mathrm{C}$ till further work. DNA samples that had been subjected to electrophoresis through agarose gels were detected by illumination with $300 \mathrm{~nm}$ UV light. The photomicrographs of DNA bands were taken by Gel-documentation system.

The isolated genomic DNA was given to Merck Millipore for actinomycetes identification service.

Culture performance in shake flask

Culture performance in shake flask was studied in the following steps. 


\section{Development of lab inoculum}

Streptomyces espinosus culture on YM slant was harvested with $5 \mathrm{ml}$ of normal saline and $0.5 \mathrm{ml}$ of suspension inoculated in YMB medium (yeast extract 4.0g/l, malt extract 10.0g/l, D-glucose 4.0g/l) $30 \mathrm{ml} / 250$ $\mathrm{ml}$ conical flask, and incubated for $48 \pm 24 \mathrm{~h}$ at $28^{\circ} \mathrm{C}$ and $240 \mathrm{rpm}$ or till optimum growth appears.

\section{Transfer of Lab inoculum into seed media}

Grown lab inoculum $(3 \%)$ at the age of $48 \mathrm{~h}$ was transferred into the seed flask media (Soluble starch $10 \mathrm{~g} / \mathrm{l}$, Peptone bacteriological $10 \mathrm{~g} / \mathrm{l}$, glycerol $3.0 \mathrm{~g} / \mathrm{l}$, yeast extract $3.0 \mathrm{~g} / \mathrm{l}$, malt extract $3.0 \mathrm{~g} / \mathrm{l}$ ). These flasks were incubated at $28^{\circ} \mathrm{C}$ at $240 \mathrm{rpm}$ up to $36 \pm 12 \mathrm{~h}$ or till growth appears.

\section{Transfer of seed inoculum into Production media}

Different media were selected from the available literature and formulated as per nutritional value (carbon and nitrogen source) $(\mathrm{P} 1-\mathrm{P} 12)$ and tested for the production of Genistein.

The selected grown seed $(10 \%)$ were transferred to production flask, and incubated at $28^{\circ} \mathrm{C}$ at $240 \mathrm{rpm}$ for $48 \mathrm{~h}$ then temperature was changed to $24.5^{\circ} \mathrm{C}$. feeding was done with anyone of the mentioned feeding solutions like $2.0 \mathrm{ml}$ of $50 \%$ dextrose $(\mathrm{pH} \mathrm{2}), 10 \%$ of glycerol $(\mathrm{pH} 2)$ and $10 \%$ dextrine white (pH 2.0) to maintain $\mathrm{pH} 6.5 \mathrm{of}$ production flask. The process parameters $\mathrm{pH}, \mathrm{PMV} \%$, microscopy analysis was monitored from $72 \mathrm{~h}$ to $312 \mathrm{~h}$.

\begin{tabular}{|l|c|c|c|c|c|c|c|c|c|c|c|c|}
\hline COMPONENTS(g/L) & P1 & P2 & P3 & P4 & P5 & P6 & P7 & P8 & P9 & P10 & P11 & P12 \\
\hline Dextrose & - & - & 20 & 25 & 20 & - & 25 & 50 & 50 & 35 & 25 & 25 \\
\hline Dextrin White & 50 & 110 & - & - & - & - & - & - & - & - & - & - \\
\hline Soluble Starch & - & - & 35 & - & - & 50 & 50 & - & - & - & 35 & 35 \\
\hline Soya Peptone & - & 12 & - & - & - & - & 5 & 15 & 5 & - & 5 & - \\
\hline Yeast Extract & - & - & - & 5 & 5 & 5 & 5 & 5 & 5 & - & 5 & - \\
\hline Malt Extract & - & - & - & 10 & 10 & 5 & 10 & 10 & 5 & - & 5 & - \\
\hline Protease Peptone & 5 & - & - & 10 & 5 & 5 & 5 & 5 & 5 & - & 5 & - \\
\hline Soyabean Flour & 15 & 8 & 30 & - & 10 & - & 10 & - & - & 25 & 10 & 15 \\
\hline Cotton Seed Flour & 10 & 10 & - & - & 5 & - & 5 & - & - & 10 & 5 & 5 \\
\hline $\mathrm{KH}_{2} \mathrm{PO}_{4}$ & 1 & 2 & 35 & 1 & 1 & 0.5 & 1 & 1 & - & 2 & 1 & 1.5 \\
\hline $\mathrm{K}_{2} \mathrm{HPO}_{4}$ & - & - & 3 & - & - & - & - & - & - & - & 0.75 & 1 \\
\hline $\mathrm{MgSO}_{4}$ & - & - & - & 1.5 & - & 0.5 & 1 & 0.5 & 1 & 2 & 1 & 1 \\
\hline $\mathrm{CaCO}_{3}$ & 2 & 2 & - & 2 & 2 & 1 & 1 & 1 & 2.5 & 2.5 & 0.5 & 2 \\
\hline$\left(\mathrm{NH}_{4}\right) \mathrm{SO}_{4}$ & - & - & 2 & - & - & - & - & - & - & - & 1 & 1 \\
\hline $\mathrm{NaCl}$ & - & - & 7 & 2 & 2 & 2 & 2 & 1 & 2 & - & 2 & 2 \\
\hline $\mathrm{Glycerol}$ & - & 8 & 30 & 20 & - & 10 & 15 & 25 & 10 & 10 & - & 10 \\
\hline $\mathrm{PEG} 400^{4}$ & 5 & 12.5 & - & 10 & - & - & - & - & - & 15 & - & - \\
\hline $\mathrm{Antifoam}_{\mathrm{Cornsteep} \mathrm{Liquor}}$ & - & - & - & - & - & - & - & - & - & - & - & - \\
\hline $\mathrm{pH}$ & 7 & 7 & - & - & 20 & - & - & - & 50 & - & - & 25 \\
\hline
\end{tabular}

\begin{tabular}{|l|c|}
\hline Trace Elements & $(\mathrm{g} / \mathbf{l})$ \\
\hline $\mathrm{ZnSO}_{4}$ & 2.0 \\
\hline $\mathrm{MnSO}_{4}$ & 0.2 \\
\hline $\mathrm{FeSO}_{4}$ & 10 \\
\hline $\mathrm{CuSO}_{4}$ & 0.2 \\
\hline
\end{tabular}

\section{Note: Add $10 \mathrm{ml}$ of trace solution to $500 \mathrm{ml}$ of each media after adjusting the $\mathbf{p H}$}

\section{Fermentation process for Genistein production}

\section{Lab Inoculum}

For Genistein production, fermentation process was carried out in the following steps:

$35 \mathrm{ml}$ medium was prepared in $250 \mathrm{ml}$ conical flask in duplicate and sterilized at $121^{\circ} \mathrm{C}$ for 30 minutes. Media Composition

Medium was prepared having the ingredients as below: 


\begin{tabular}{|lc|}
\hline Components & g/l \\
Yeast Extract & 4.0 \\
Malt Extract & 10.0 \\
D-glucose & 4.0 \\
pH & \\
Actual & 6.5 \\
& \\
Adjusted & 6.8 \\
& \\
After Sterilization & 6.62 \\
\hline
\end{tabular}

\section{Inoculation and Incubation}

Culture suspension from a slant was prepared and inoculated into two conical flasks containing $35 \mathrm{ml}$ sterilized medium under aseptic condition and flask was placed on shaking incubator at $28{ }^{\circ} \mathrm{C}, 240 \mathrm{rpm}$ for $48 \mathrm{~h}$.

\section{Maturity of Lab Inoculum}

The $\mathrm{pH}$ of matured inoculum was observed under range of 6.0 to 6.5 where the packed mass volume was 4.0 to $5.0 \%$. Filamentous growth with good mycelial network was observed under microscope (100X).

\section{Seed flask (5 Liters)}

$30 \mathrm{ml}$ of grown inoculum was inoculated into seed flask (5 Liter) with volume of $750 \mathrm{ml}$ media in duplicate and flask was incubated on shaking incubator at $28{ }^{\circ} \mathrm{C}, 240 \mathrm{rpm}$ for $48 \mathrm{~h}$.

\section{Media Composition for Seed media-}

The ingredients used in the Seed medium are given below.

\begin{tabular}{|ll|}
\hline Components & $\mathbf{g} / \mathbf{l}$ \\
Soluble starch & 10.0 \\
Bacteriological peptone & 10.0 \\
& \\
Glycerol & 3.0 \\
Yeast extract & 3.0 \\
Malt extract & 3.0 \\
pH & \\
Actual & 6.8 \\
Adjusted to & 7.2 \\
After sterilization & 7.0 \\
\hline
\end{tabular}

\section{Production Fermenter (22 Litres)}

The vessel was physically checked for proper cleaning; availability of utility was also checked before start of batch. The vessel was made ready by doing following process stepwise: Cleaning in Place (CIP), leak test of fermenter, empty sterilization, activation and calibration of $\mathrm{pH}$ and $\mathrm{DO}$ probe, media preparation and sterilization (working volume 12 litre) were done as described for $22 \mathrm{~L}$ production fermenter.

\section{Media Composition for $22 \mathrm{~L}$ fermenter-}

The ingredients used in the fermentation medium given below. 


\begin{tabular}{|c|c|}
\hline \multicolumn{2}{|c|}{ Production media (Z2) } \\
\hline Components & $\mathrm{g} / \mathrm{l}$ \\
\hline Dextrine white & 100.0 \\
\hline Soya peptone & 10.0 \\
\hline Cotton seed flour & 10.0 \\
\hline Glycerol & 10.0 \\
\hline PEG 400 & 12.5 \\
\hline $\mathrm{KH}_{2} \mathrm{PO}_{4}$ & 2.0 \\
\hline $\mathrm{CaCO}_{3}$ & 2.0 \\
\hline Trace solution & $20.0 \mathrm{ml}$ \\
\hline \multicolumn{2}{|l|}{ pH } \\
\hline Actual & 6.6 \\
\hline Adjusted to & 7.0 \\
\hline After sterilization & 6.56 \\
\hline
\end{tabular}

\begin{tabular}{|l|c|}
\hline Trace Elements & (g/l) \\
\hline $\mathrm{ZnSO}_{4}$ & 2.0 \\
\hline $\mathrm{MnSO}_{4}$ & 0.2 \\
\hline $\mathrm{FeSO}_{4}$ & 10 \\
\hline $\mathrm{CuSO}_{4}$ & 0.2 \\
\hline
\end{tabular}

Note: $20 \mathrm{ml}$ of trace solution to $1000 \mathrm{ml}$ of each media after adjusting the $\mathrm{pH}$

After maturity of seed, 1.2 liter of seed volume was transferred to production vessel. The $\mathrm{pH}$ of matured seed was observed to be 7.2 where the packed mass volume was $8 \%$. The initial parameters were set to air $0.5 \mathrm{vvm}$ and gradually increased to $2.0 \mathrm{vvm}$. Initially agitation was set to $200 \mathrm{rpm}$ which was raised upto $600 \mathrm{rpm}$. Back pressure was set to $0.5 \mathrm{~kg} / \mathrm{cm}^{2}$ and increased upto $1.07 \mathrm{~kg} / \mathrm{cm}^{2}$ as process required till the age of $288 \mathrm{~h}$.

\section{Assay, Purification \& Characterization of Genistein}

HPLC grade methanol, ethyl acetate and acetonitrile were purchased from Merck India Limited, Mumbai, India. Deionized water was prepared using MilliQ plus purification system (Millipore, Bradford, USA). Potassium bromide (FTIR grade), DMSO- $\mathrm{D}_{6}, \mathrm{CDCl}_{3}-\mathrm{D}_{1}$ and $\mathrm{D}_{2} \mathrm{O}_{-} \mathrm{D}_{2}$ were purchased from Merck KGaA, Darmstadt, Germany.

\subsection{High performance liquid chromatography}

Samples were analyzed on Alliance 2690 HPLC (Waters, Milford, MA, USA) system equipped with 2487 UV detector. A Hypersil BDS C18 column ( $250 \mathrm{~mm} \times 4.6 \mathrm{~mm}$ i.d. $5 \mu \mathrm{m}$ Thermo scientific, USA) was used for chromatographic separation. The mobile phase consisting of A: water: acetonitrile $(70: 30, \mathrm{v} / \mathrm{v})$ and $\mathrm{B}$ : water, with timed gradient programme T (min)/ B (\%): 0/20, 17/70, 22/80, 23/50, 25/20, 30/20 with flow rate of $1.0 \mathrm{ml}$ per minute was used. The injection volume was $20 \mu \mathrm{L}$ and the detector wavelength was fixed at $260 \mathrm{~nm}$.

\subsection{Mass spectrometry}

The LC-ESI/MS and MS/MS analysis was carried out on LCQ-Advantage (Thermo Finnigan, San Jose, CA, USA) ion trap mass spectrometer. The LC part was consisted of an Agilent 1100 series quaternary gradient pump with a degasser and auto sampler. The chromatographic condition described in section 2.2 has been used for the analysis. The source voltage was kept at $3.0 \mathrm{kV}$ and capillary temperature at $250{ }^{\circ} \mathrm{C}$. Nitrogen was used 
as both sheath and auxiliary gas. Mass range was kept at $\mathrm{m} / \mathrm{z} 50-500$. MS/MS studies were carried out by maintaining normalized collision energy at $30 \%$ with the mass range $\mathrm{m} / \mathrm{z} 50-500$.

\subsection{Semi-preparative HPLC}

The unknown impurity was isolated from crude sample of genistein using Waters Auto-purification system consisting of 2525 binary gradient pump, a 2487 UV detector and 2767 sample manager (Waters, Milford, MA, USA). A Peerless Basic C18 Column (250 mm X $21.2 \mathrm{~mm}$ ID, particle size 5 $\mu \mathrm{m})$, USA was used for preparative isolation. The mobile phase consisting of A: water: acetonitrile $(70: 30, \mathrm{v} / \mathrm{v})$ and $\mathrm{B}$ : water, with timed gradient programme $\mathrm{T}(\mathrm{min}) / \mathrm{B}(\%)$ : 0/100, 10/100, 11/0, 80/00 with flow rate of $35.0 \mathrm{ml}$ per minute was used. The injection volume was $5.0 \mathrm{~mL}$ and the detector wavelength was fixed at $260 \mathrm{~nm}$.

\subsection{NMR}

The ${ }^{1} \mathrm{H},{ }^{13} \mathrm{C}$ measurements of synthetically prepared impurity sample were recorded on a AVANCE 400 (Bruker, Fallanden, Switzerland) instrument at 300 K. DEPT spectral editing revealed the presence of methyl and methine groups as positive peaks while the methylenes as negative peaks. The exchangeable protons were identified by $\mathrm{D}_{2} \mathrm{O}$ exchange experiment. The phase sensitive double quantum filtered correlation spectroscopy (DQF-COSY), hetronuclear single quantum correlation (HSQC) and nuclear Overhauser effect spectroscopy (NOESY) was also performed using the same instrument. The ${ }^{1} \mathrm{H}$ and ${ }^{13} \mathrm{C}$ chemical shift values were reported on the $\delta$ scale in ppm relative to DMSO- $\mathrm{d}_{6}(2.50 \mathrm{ppm})$ and $(39.5 \mathrm{ppm})$ respectively.

\subsection{IR spectroscopy}

The IR spectrum of isolated impurity was recorded in the solid state $\mathrm{KBr}$ powder dispersion using a Spectrum-One FT-IR spectrometer (PerkinElmer, Beaconsfield, UK).

\section{Results}

Fifty three filamentous bacterial isolates were isolated from total of ten soil sample collected from different sites of Mumbai out of which one colony was found to produce Genistein which could be used for further studies and it was termed as Z. On YM plates isolate Z colonies were pin-point in size, circular in shape, regular in margin, umbonate in elevation, dark pink in colour with opacity, hard to pick and sporulate with age The isolate $\mathrm{Z}$ gives morphological similarity to that of a Streptomyces espinosus with a distinct mycelium as observed through light microscopy. Isolate $\mathrm{Z}$ was gram positive, non-motile with Nitrate and sugar fermentation positive while Oxidase, Catalase, Citrate, MR-VP, Starch Hydrolysis, Casein hydrolysis, Fluorescence assay, Indole production was negative as shown in Figure 1 and Table 1.

Figure 1: Genistein producing strain Streptomyces espinosus Z. (A) Growth and colony morphology of S. espinosus on YMA plate; (B) Morphological characterization of S. espinosus through light microscopy
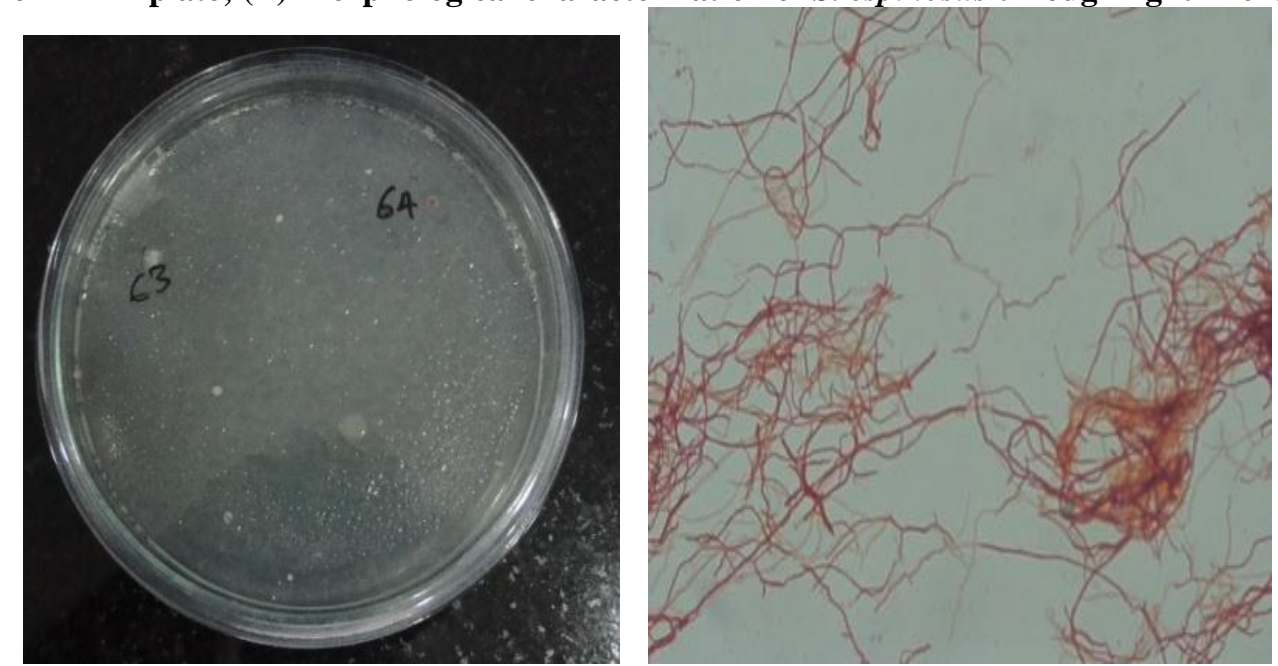
Isolation, screening and characterization of Streptomyces espinosus from rhizospheric soil ...

Table 1: Morphological, physiological and biochemical characteristics of actinomycetes isolate $Z$

\begin{tabular}{ccc}
\hline S.No. & Characteristics & Actinomycetes isolate Z \\
\hline 1 & Soil sample & Garden soil \\
2 & Colony no. & Z \\
3 & Size & Pinpoint \\
4 & Shape & Circular \\
5 & Margin & Regular \\
6 & Elevation & Umbonate \\
7 & Colour & Dark Pink \\
8 & Opacity & Opaque \\
9 & Consistency & Hard to pick and sporulation with age \\
10 & Gram reaction & Positive \\
11 & Microscopic shape & Mycelial growth \\
12 & Motility & Non-motile \\
13 & Oxidase & - \\
14 & Nitrate & - \\
15 & Catalase & - \\
16 & Citrate & - \\
17 & MR-VP & - \\
18 & Starch Hydrolysis & - \\
19 & Casein Hydrolysis & - \\
20 & Fluorescence assay & + \\
21 & Sugar fermentation & - \\
22 & Indole production & \\
\hline
\end{tabular}

\section{Molecular characterization}

\section{Isolation of genomic DNA and amplification of 16S rRNA gene}

Genomic DNA was isolated from S. espinosus as shown in Figure. Further, it was used for the amplification and sequencing assessment. The 16S rRNA gene of the isolates was amplified by using universal primers Univ F and Univ R. The amplified products were compared with low range ruler DNA. The size of amplified product was approximately $1500 \mathrm{bp}$ which represented the amplification of nearly full length $16 \mathrm{~S}$ rRNA gene from the isolates. The size of the PCR product corresponded with the size of the 16S rRNA genes among the isolates (Figure 2).

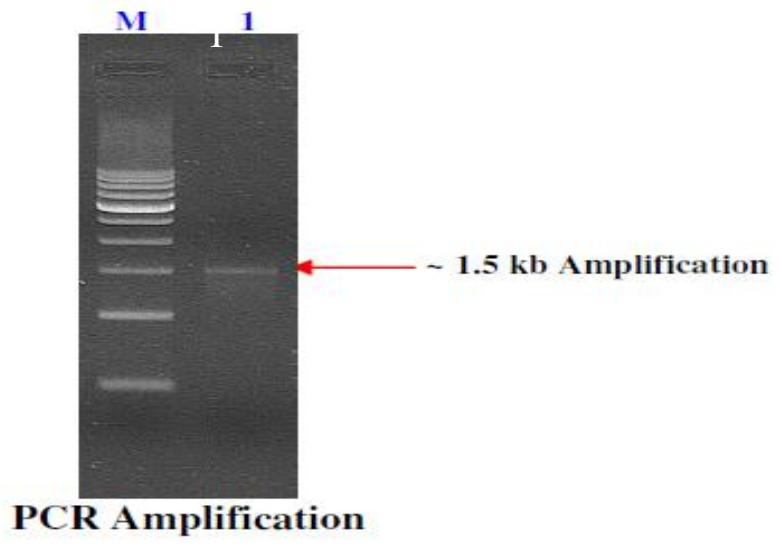

Abbreviation: M: Marker; 1: Sample

Figure 2: Amplified 16S rDNA gene of S. espinosus.

\section{Characterization of strain on the basis of $16 \mathrm{~S}$ rDNA sequencing}

The strain was identified for their taxonomic position on the basis of phylogenetic analysis of $16 \mathrm{~S}$ rDNA sequences. The strain Z was identified as Streptomyces espinosus (Figure 3).

\section{Phylogenetic analysis}


A neighbour joining dendogram was prepared using $16 \mathrm{~S}$ rDNA sequences of Streptomyces espinosus Z and representative sequences from EMBL/Gen Bank/DDBJ and PDB. Gene sequence was used to carry out BLAST with the nrdatabase of NCBI genbank database. Based on maximum identity score first ten sequences were selected the phylogenetic tree was constructed using MEGA 4.

Two major clades were observed in which isolate Z clustered with Streptomyces espinosus (X80826) with $97 \%$ bootstrap values (Figure). Based on nucleotides homology and phylogenetic analysis the microbe (Sample: DSPORE) was found to be Streptomyces espinosus (GenBank Accession Number: X80826). Nearest homolog was found to be Streptomyces sp. Durck 47 (GenBank Accession Number: HE664170).

The evolutionary history was inferred using the Neighbor-Joining method. The bootstrap consensus tree inferred from 1000 replicates is taken to represent the evolutionary history of the taxa analyzed. Branches corresponding to partitions reproduced in less than 50\% bootstrap replicates are collapsed. The percentage of replicate trees in which the associated taxa clustered together in the bootstrap test (1000 replicates) is shown next to the branches. The evolutionary distances were computed using the Kimura 2-parameter method and are in the units of the number of base substitutions per site. Codon positions included were $1 \mathrm{st}+2 \mathrm{nd}+3 \mathrm{rd}+$ Noncoding. All positions containing gaps and missing data were eliminated from the dataset (Complete deletion option). There were a total of 603 positions in the final dataset. Phylogenetic analyses were conducted in MEGA4.

The 16S rDNA sequences of the Streptomyces espinosus Z

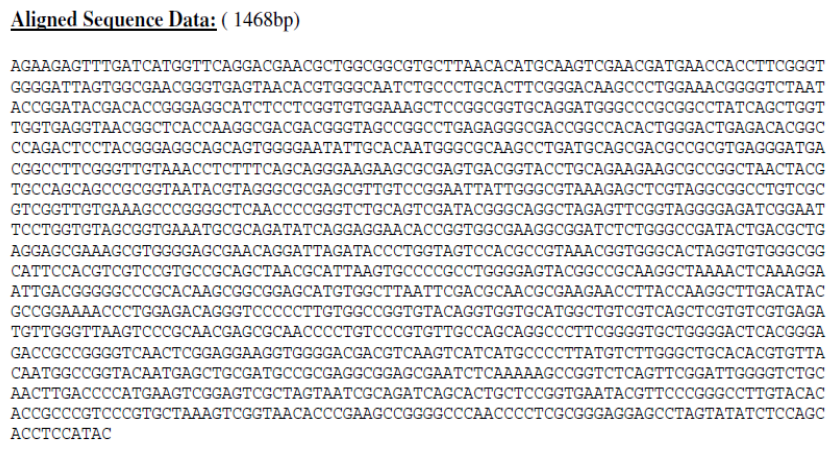

\begin{tabular}{|c|c|c|c|}
\hline Alignment View & ID & Alignment results & Sequence Description \\
\hline$\square$ & $\underline{\text { Sample Z }}$ & 1.00 & Studied Sample \\
\hline$\square$ & HE664170 & 0.97 & Streptomyces sp.Durck 47 st.Durck 47 \\
\hline$\square$ & $\underline{X 0826}$ & 0.97 & Streptomyces espinosus st.NRRL 5729 \\
\hline$\square$ & $\underline{\mathrm{AB} 184662}$ & 0.95 & $\begin{array}{c}\text { Streptomyces ghanaensis st.NBRC } \\
15414\end{array}$ \\
\hline$\square$ & $\underline{\mathrm{JX204833}}$ & 0.96 & Streptomyces caelestis st.AW9_9C \\
\hline$\square$ & $\underline{\text { GU045531 }}$ & 0.96 & Streptomyces sp.SXY48 \\
\hline$\square$ & $\underline{\mathrm{HQ} 850413}$ & 0.95 & Streptomyces cellulosae st.S44 \\
\hline$\square$ & EF371427 & 0.95 & Streptomyces vinaceus st.3078 \\
\hline$\square$ & $\underline{E F 626594}$ & 0.95 & $\begin{array}{c}\text { Streptomyces brasiliensis st.NRRL B- } \\
3327\end{array}$ \\
\hline$\square$ & $\underline{\text { GU433227 }}$ & 0.96 & Streptomyces calvus st.ABRIINW 673 \\
\hline$\square$ & $\underline{\mathrm{AY} 999902}$ & 0.95 & $\begin{array}{l}\text { Streptomyces asterosporus st.NRRL B- } \\
24328\end{array}$ \\
\hline
\end{tabular}

\begin{tabular}{|c|c|c|c|c|c|c|c|c|c|c|c|}
\hline & 1 & 2 & 3 & 4 & 5 & 6 & 7 & 8 & 9 & 10 & 11 \\
\hline 12 & 0.000 & 0.062 & 0.105 & 0.101 & 0.117 & 0.123 & 0.095 & 0.095 & 0.102 & 0.115 & 0.114 \\
\hline 2 HE 664170 & 0.062 & 0.000 & 0.056 & 0.041 & 0.074 & 0.080 & 0.054 & 0.051 & 0.059 & 0.072 & 0.071 \\
\hline $3 \times 80826$ & 0.105 & 0.056 & 0.000 & 0.064 & 0.054 & 0.050 & 0.077 & 0.074 & 0.057 & 0.038 & 0.068 \\
\hline 4 AB184662 & 0.101 & 0.041 & 0.064 & 0.000 & 0.090 & 0.095 & 0.082 & 0.079 & 0.072 & 0.084 & 0.085 \\
\hline 5 JX204833 & 0.117 & 0.074 & 0.054 & 0.090 & 0.000 & 0.014 & 0.033 & 0.030 & 0.040 & 0.033 & 0.047 \\
\hline 6 GU045531 & 0.123 & 0.080 & 0.050 & 0.095 & 0.014 & 0.000 & 0.040 & 0.038 & 0.045 & 0.029 & 0.054 \\
\hline $7 \mathrm{HQ} 850413$ & 0.095 & 0.054 & 0.077 & 0.082 & 0.033 & 0.040 & 0.000 & 0.004 & 0.044 & 0.056 & 0.057 \\
\hline 8 EF371427 & 0.095 & 0.051 & 0.074 & 0.079 & 0.030 & 0.038 & 0.004 & 0.000 & 0.041 & 0.053 & 0.055 \\
\hline $9 \mathrm{EF} 626594$ & 0.102 & 0.059 & 0.057 & 0.072 & 0.040 & 0.045 & 0.044 & 0.041 & 0.000 & 0.035 & 0.032 \\
\hline 10 GU4 33227 & 0.115 & 0.072 & 0.038 & 0.084 & 0.033 & 0.029 & 0.056 & 0.053 & 0.035 & 0.000 & 0.033 \\
\hline 11 AY999902 & 0.114 & 0.071 & 0.068 & 0.085 & 0.047 & 0.054 & 0.057 & 0.055 & 0.032 & 0.033 & 0.000 \\
\hline
\end{tabular}

Alignment view using combination of NCBI GenBank and RDP database

Distance Matrix based on Nucleotide Sequence Homology (Using Kimura-2 Parameter)

Distance Matrix based on Nucleotide Sequence Homologv (Using Kimura-2 Parameter): 
Table indicates nucleotide similarity (above diagonal) and distance (below diagonal) identitie between the studied sample 'Sample-Z' and ten other closest homologous microbe.

Phylogenetic Tree made using Neighbor Joining method:

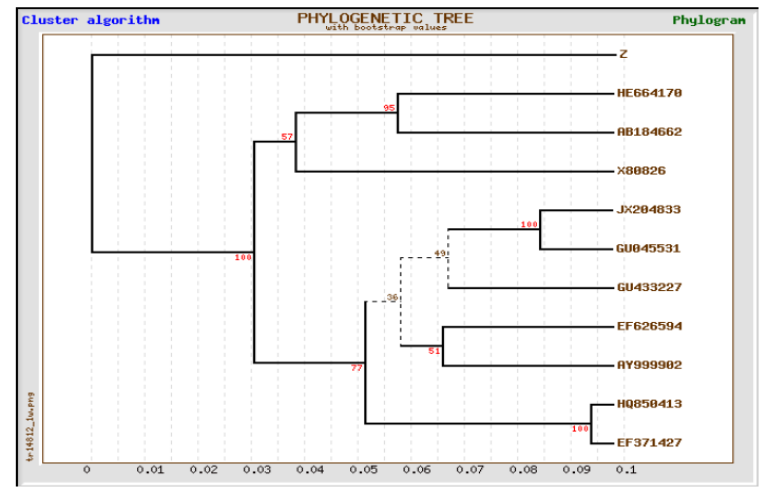

Figure 3: Phylogenetic relationship between Streptomyces espinosus Z and representative Streptomyces sp. based on partial 16S rDNA sequences. The tree was constructed by maximum parsimony method based on $16 \mathrm{~S}$ rDNA sequences. Accession number of strains is shown in dendogram. Number above the branches is bootstrap values based on 1000 replicates with fast step-wise addition.

\section{Culture performance in shake flask}

S. espinosus was inoculated in lab inoculum, then $3 \%$ of $48 \mathrm{~h}$ grown lab inoculum was transferred into seed medium. Later $10 \%$ of matured seed was transferred to different production medium for Genistein production. In process parameters, i.e. pH, PMV was measured at different interval as shown in Table 2.

Table 2: Analysis of process parameter in P1 to P12 Production medium

\begin{tabular}{|c|c|c|c|c|c|c|c|}
\hline Production & Time (h) & $\mathbf{p H}$ & PMV (\%) & $\begin{array}{c}\text { Producti } \\
\text { on }\end{array}$ & Time (h) & pH & $\begin{array}{c}\text { PMV } \\
(\%) \\
\end{array}$ \\
\hline & 72 & 6.43 & - & & 72 & 6.79 & - \\
\hline \multirow[t]{7}{*}{ P1 } & 120 & 6.97 & - & P9 & 120 & 5.98 & - \\
\hline & 168 & 5.34 & 15 & & 168 & 7.44 & 25 \\
\hline & 216 & 7.73 & 30 & & 216 & 7.28 & 25 \\
\hline & 264 & 6.04 & 25 & & 264 & 7.36 & 25 \\
\hline & 312 & 7.00 & 45 & & 312 & 7.43 & 30 \\
\hline & 72 & 6.17 & - & & 72 & 6.16 & - \\
\hline & 120 & 5.64 & - & & 120 & 4.98 & - \\
\hline \multirow[t]{6}{*}{$\mathbf{P 2}$} & 168 & 6.45 & 25 & P10 & 168 & 4.88 & 15 \\
\hline & 216 & 6.62 & 30 & & 216 & 4.77 & 15 \\
\hline & 264 & 6.7 & 30 & & 264 & 5.84 & 25 \\
\hline & 312 & 6.45 & 55 & & 312 & 8.28 & 50 \\
\hline & 72 & 5.25 & - & & 72 & 5.62 & - \\
\hline & 120 & 4.68 & - & & 120 & 5.15 & - \\
\hline \multirow[t]{6}{*}{ P3 } & 168 & 4.61 & 30 & P11 & 168 & 5.62 & 20 \\
\hline & 216 & 4.63 & 10 & & 216 & 5.8 & 20 \\
\hline & 264 & 5.3 & 30 & & 264 & 6.98 & 20 \\
\hline & 312 & 4.55 & 25 & & 312 & 7.77 & 25 \\
\hline & 72 & 6.57 & - & & 72 & 5.78 & - \\
\hline & 120 & 7.22 & - & & 120 & 5.34 & - \\
\hline \multirow[t]{5}{*}{ P4 } & 168 & 7.2 & 20 & P12 & 168 & 5.94 & 20 \\
\hline & 216 & 7.97 & 25 & & 216 & 6.42 & 30 \\
\hline & 264 & 7.48 & 20 & & 264 & 6.28 & 25 \\
\hline & 312 & 6.03 & 30 & & 312 & 4.93 & 20 \\
\hline & 72 & 6.66 & - & & & & \\
\hline \multirow[t]{7}{*}{ P5 } & 120 & 6.17 & - & & & & \\
\hline & 168 & 7.5 & 35 & & & & \\
\hline & 216 & 8.17 & 35 & & & & \\
\hline & 264 & 7.74 & 40 & & & & \\
\hline & 312 & 7.5 & 43 & & & & \\
\hline & 72 & 7.09 & - & & & & \\
\hline & 120 & 7.1 & - & & & & \\
\hline \multirow[t]{6}{*}{ P6 } & 168 & 6.4 & 15 & & & & \\
\hline & 216 & 7.0 & 15 & & & & \\
\hline & 264 & 7.63 & 20 & & & & \\
\hline & 312 & 7.63 & 15 & & & & \\
\hline & 72 & 5.75 & - & & & & \\
\hline & 120 & 5.09 & - & & & & \\
\hline P7 & 168 & 5.52 & 25 & & & & \\
\hline
\end{tabular}


Isolation, screening and characterization of Streptomyces espinosus from rhizospheric soil ...

\begin{tabular}{cccc}
\hline & & & \\
& 216 & 6.03 & 20 \\
& 264 & 5.7 & 10 \\
& 312 & 7.52 & 40 \\
72 & 6.7 & - \\
$\mathbf{P 8}$ & 120 & 4.97 & - \\
& 168 & 4.63 & 15 \\
& 216 & 4.55 & 10 \\
& 264 & 4.24 & 10 \\
\hline
\end{tabular}

\section{Fermentation process for Genistein production}

\section{Maturity of Lab Inoculum}

At $48 \mathrm{~h}, \mathrm{pH}$ and PMV of lab inoculum was 6.6 and $3 \%$, respectively. Filamentous growth with good mycelial network was observed through microcopy without any contamination. $35 \mathrm{ml}$ of said inoculum was inoculated into seed flask with volume of $750 \mathrm{ml}$ seed media.

\section{Seed inoculum}

At $48 \mathrm{~h}, \mathrm{pH}$ and PMV of seed inoculum was 7.14 and $8 \%$, respectively. Microscopic observations looked like filamentous growth with good mycelia network. 1.5 liter of grown seed was transferred into production fermenter with volume of 12 liter.

\section{Production Fermenter}

In process parameters (such as $\mathrm{pH}, \mathrm{PMV}, \mathrm{DO}$, air, $\mathrm{BP}, \mathrm{RPM}$ ) were measured in production medium at different intervals (Table 3). $\mathrm{pH}$ was maintained by feeding $10 \%$ dextrine white of $\mathrm{pH} \mathrm{2.0.} \mathrm{At} \mathrm{the} \mathrm{start} \mathrm{of}$ fermentation process following parameters of medium were taken into account, such as at $0 \mathrm{~h}$ temperature $28.1^{\circ} \mathrm{C}$, pH 6.35, PMV $7 \%$. DO, air, BP and speed were recorded as $100 \%, 17 \mathrm{LPM}, 0.60 \mathrm{~kg} / \mathrm{cm}^{2}, 200 \mathrm{RPM}$, respectively. The results of HPLC assays showed that the organism started producing Genistein from $72 \mathrm{~h}$. At $72 \mathrm{~h}, \mathrm{RPM}$ increased to 600 and air by $48 \mathrm{LPM}$. At 96 h, pH, PMV, DO, BP were measured as 6.35, 20 \%, 52\%, $0.63 \mathrm{~kg} / \mathrm{cm}^{2}$. Air remained the same $48 \mathrm{LPM}$ and RPM to 600 . At $120 \mathrm{~h}$, DO came down to $39.6 \%$ and air to 45 LPM. At $144 \mathrm{~h}$, air decreased to 28 LPM, DO was $35.1 \%$. At $160 \mathrm{~h}$, parameters like DO 27.2 \%, air 28 LPM and 500 RPM were set. At 203 h, DO was $19.8 \%$, air and RPM were 28 LPM, 500 respectively. The packed mycelium volume gradually increases up to $26 \%$. pH 6.5-7.0 was maintained by feeding of $10 \%$ dextrine white of $2.0 \mathrm{pH}$. Production batch was ran at $28^{\circ} \mathrm{C}$ upto $48 \mathrm{~h}$ and then shift to $25^{\circ} \mathrm{C}$ temperature. Batch was started with 200 RPM and 17 liter/minute air (i.e. 0.9 VVM). Back pressure rose up to $1.03 \mathrm{~kg} / \mathrm{cm}^{2}$ (Table 3 and 4).

Table 3: Analysis of process parameter in fermenter production medium

\begin{tabular}{|c|c|c|c|c|c|c|c|c|}
\hline $\begin{array}{c}\text { Age } \\
(\mathbf{H r s})\end{array}$ & $\begin{array}{c}\text { Temp } \\
\left({ }^{\circ} \mathbf{C}\right)\end{array}$ & $\mathbf{p H}$ & $\begin{array}{c}\text { PMV } \\
(\boldsymbol{\%})\end{array}$ & $\begin{array}{c}\text { Air } \\
(\mathbf{L P M})\end{array}$ & $\begin{array}{c}\text { Speed } \\
(\mathbf{R P M})\end{array}$ & $\begin{array}{c}\text { B.P } \\
(\mathbf{K g} / \mathbf{c m})\end{array}$ & $\begin{array}{c}\text { D.O } \\
(\boldsymbol{\%})\end{array}$ & $\begin{array}{c}\text { Vol. } \\
(\mathbf{l i t e r s})\end{array}$ \\
\hline 0 & 28.1 & 6.35 & 07 & 17 & 200 & 0.60 & 100 & 34.5 \\
\hline 04 & 28.1 & 6.34 & 07 & 17 & 200 & 0.62 & 100 & - \\
\hline 08 & 27.9 & 6.34 & 07 & 17 & 200 & 0.58 & 100 & - \\
\hline 11 & 28.1 & 6.38 & 08 & 17 & 250 & 0.65 & 100 & - \\
\hline 16 & 28.1 & 6.18 & 08 & 17 & 250 & 0.65 & 100 & - \\
\hline 20 & 28.0 & 6.11 & 11 & 17 & 300 & 0.61 & 100 & - \\
\hline 24 & 28.0 & 6.01 & 12 & 17 & 350 & 0.63 & 100 & - \\
\hline 32 & 28.0 & 5.74 & 16 & 17 & 400 & 0.63 & 100 & - \\
\hline 40 & 28.0 & 5.64 & 20 & 17 & 400 & 0.56 & 100 & - \\
\hline 48 & 25.0 & 5.62 & 17 & 17 & 500 & 0.62 & 100 & - \\
\hline 56 & 25.0 & 5.86 & 17 & 25 & 550 & 0.63 & 95 & 32 \\
\hline 64 & 25.2 & 5.96 & 17 & 25 & 550 & 0.61 & 82.8 & - \\
\hline 68 & 25.1 & 6.02 & 20 & 32 & 600 & 0.53 & 77.8 & - \\
\hline 72 & 25.0 & 6.05 & 19 & 48 & 600 & 0.59 & 73.6 & - \\
\hline 80 & 25.0 & 6.10 & 19 & 48 & 600 & 0.62 & 65.9 & 30 \\
\hline 88 & 24.8 & 6.38 & 19 & 48 & 600 & 0.65 & 61.3 & - \\
\hline 96 & 25.0 & 6.35 & 20 & 48 & 600 & 0.63 & 52.1 & - \\
\hline 104 & 25.0 & 6.66 & 20 & 60 & 600 & 0.62 & 47.4 & - \\
\hline 112 & 25.0 & 6.92 & 21 & 60 & 600 & 0.64 & 46.8 & - \\
\hline
\end{tabular}


Isolation, screening and characterization of Streptomyces espinosus from rhizospheric soil ...

\begin{tabular}{|l|c|c|c|c|c|c|c|c|}
\hline 116 & 25.0 & 6.99 & 20 & 60 & 600 & 0.65 & 42.4 & - \\
\hline 120 & 25.0 & 7.03 & 18 & 45 & 600 & 0.80 & 39.6 & - \\
\hline 124 & 25.0 & 6.93 & 17 & 45 & 600 & 1.05 & 37.6 & - \\
\hline 128 & 25.0 & 7.10 & 20 & 45 & 600 & 1.02 & 40.4 & - \\
\hline 136 & 24.9 & 6.96 & 23 & 45 & 600 & 1.09 & 36.7 & - \\
\hline 140 & 25.0 & 7.14 & 25 & 45 & 600 & 1.0 & 34.8 & - \\
\hline 144 & 25.0 & 7.10 & 23 & 28 & 500 & 1.02 & 40.1 & - \\
\hline 148 & 25.0 & 7.06 & 22 & 28 & 500 & 1.02 & 45.0 & - \\
\hline 152 & 25.0 & 7.02 & 21 & 28 & 500 & 1.06 & 48.2 & - \\
\hline 160 & 25.0 & 7.08 & 21 & 28 & 500 & 1.03 & 52.0 & - \\
\hline 176 & 25.0 & 7.10 & 21 & 28 & 500 & 1.05 & 55.0 & - \\
\hline 200 & 24.9 & 7.15 & 21 & 28 & 500 & 1.05 & 60.2 & - \\
\hline 203 & 25.1 & 7.25 & 26 & 28 & 500 & 1.03 & 62.3 & - \\
\hline 210 & 25.0 & 7.40 & 28 & 28 & 500 & 1.03 & 63.0 & - \\
\hline 220 & 25.2 & 7.49 & 30 & 28 & 500 & 1.02 & 65.2 & 24 \\
\hline
\end{tabular}

Temperature $\left({ }^{\circ} \mathrm{C}\right): 0-42 \mathrm{hrs} .=28,43$ to $203 \mathrm{hrs}=25$.

Agitation (RPM): $0-8$ Hrs. $=200,9-18$ Hrs. $=250,19-23$ Hrs. $=300,24-31$ Hrs. $=350,32-40$ Hrs. $=400,41$ $-43 \mathrm{hrs}=450,44-55 \mathrm{hrs}=500,56-67=550,68-143=600,144-203 \mathrm{hrs}=500$.

Air (LPM): $0-48$ Hrs. $=17,49-64=25,65-71 \mathrm{Hrs}=32,72-96=48,97-116=60,117-140 \mathrm{hrs}=45,141$ $-203 \mathrm{hrs}=28$.

Back Pressure $\left(\mathrm{Kg} / \mathrm{cm}^{2}\right): 0$ - 120 Hrs. $=0.60,121-203 \mathrm{hrs}=1.0$.

Feeding detail:

\begin{tabular}{|c|c|c|}
\hline Age (Hrs) & Feeding Solution & Feeding Volume (Liters) \\
\hline 113 & $10 \%$ Dextrine white $(\mathrm{pH} 2.0)$ & 0.5 \\
\hline 129 & $10 \%$ Dextrine white $(\mathrm{pH} 2.0)$ & 0.5 \\
\hline
\end{tabular}

Table 4: Analysis of process parameter in fermenter production medium

\begin{tabular}{|c|c|c|c|c|c|c|c|c|c|c|c|c|c|c|}
\hline $\begin{array}{l}\text { Age } \\
\text { (Hrs.) }\end{array}$ & Temp. & $\mathrm{pH}$ & $\begin{array}{l}\text { PMV } \\
(\%)\end{array}$ & $\begin{array}{c}\text { TS } \\
(\mathrm{g} / \mathrm{l})\end{array}$ & $\begin{array}{l}\text { RS } \\
(g / l)\end{array}$ & $\begin{array}{l}\mathrm{PO}_{4} \\
(\mathrm{~g} / \mathrm{l})\end{array}$ & $\begin{array}{c}\mathrm{NH}_{3} \mathrm{~N} \\
(\mathrm{~g} / \mathrm{l})\end{array}$ & $\begin{array}{l}\text { D.0. } \\
(\%)\end{array}$ & $\begin{array}{c}\text { Air } \\
\text { (LPM) }\end{array}$ & $\begin{array}{c}\text { B.P. } \\
\left(\mathrm{K} / \mathrm{cm}^{2}\right)\end{array}$ & $\begin{array}{l}\text { Speed } \\
\text { (RPM) }\end{array}$ & $\begin{array}{l}\text { Temp. }{ }^{\circ} \mathrm{C} \\
\left(20^{\circ} \mathrm{C}=0\right)\end{array}$ & $\begin{array}{c}\text { Speed } \\
(\mathrm{rpm} / 1 \\
00)\end{array}$ & $\begin{array}{c}\text { Air } \\
\text { (VVM) }\end{array}$ \\
\hline 0 & 28.1 & 6.35 & 7 & 75.32 & 14.25 & 0.056 & 0.418 & 100.0 & 17 & 0.60 & 200 & 8.10 & 2.00 & 0.50 \\
\hline 8 & 27.9 & 6.34 & 7 & 70.84 & 20.57 & 0.055 & 0.339 & 100.0 & 17 & 0.58 & 200 & 7.90 & 2.00 & 0.50 \\
\hline 32 & 28.0 & 5.74 & 16 & 66.11 & 26.33 & 0.046 & 0.258 & 100.0 & 17 & 0.63 & 400 & 8.00 & 4.00 & 0.50 \\
\hline 56 & 25.0 & 5.86 & 17 & 59.36 & 30.38 & 0.050 & 0.229 & 96.2 & 25 & 0.62 & 500 & 5.00 & 5.00 & 0.75 \\
\hline 80 & 25,0 & 6.10 & 19 & 49.20 & 34.11 & 0.048 & 0.298 & 65.5 & 48 & 0.62 & 600 & 5,00 & 6.00 & 1.50 \\
\hline 104 & 25.0 & 6.66 & 20 & 38.23 & 41.36 & 0.046 & 0.280 & 47.4 & 60 & 0.62 & 600 & 5.00 & 6.00 & 2.00 \\
\hline 128 & 25.0 & 7.10 & 20 & 35.52 & 50.18 & 0.031 & 0.223 & 40.4 & 45 & 1.02 & 600 & 5.00 & 6.00 & 1.50 \\
\hline 152 & 25.0 & 7.02 & 21 & 30.35 & 43.66 & 0.034 & 0.279 & 48.2 & 28 & 1.06 & 500 & 5.00 & 5.00 & 1.00 \\
\hline 176 & 25.0 & 7.10 & 21 & 29.95 & 34.58 & 0.031 & 0.249 & 55.0 & 28 & 1.05 & 500 & 5.00 & 5.00 & 1.00 \\
\hline 203 & 25.1 & 7.25 & 26 & 26.17 & 29.33 & 0.029 & 0.269 & 62.3 & 28 & 1.03 & 500 & 5.10 & 5.00 & 1.00 \\
\hline 210 & 25.0 & 7.40 & 28 & 20.56 & 20.23 & 0.028 & 0.260 & 63.0 & 28 & 1.03 & 500 & 5.10 & 5.00 & 1.00 \\
\hline 220 & 25.2 & 7.49 & 30 & 15.59 & 10.36 & 0.023 & 0.251 & 65.2 & 28 & 1.02 & 500 & 5.20 & 5.00 & 1.00 \\
\hline
\end{tabular}

Assay, Purification \& Characterization of Genistein 
The material obtained from production media was centrifuged at $4700 \mathrm{rpm}$ for 10 minutes at $25{ }^{\circ} \mathrm{C}$. The settled cake from this process was then extracted with ethyl acetate. $2.5 \mathrm{~mL}$ of this extract was diluted to 25 $\mathrm{mL}$ with methanol. The HPLC chromatograph showed the major peak at $10.48 \mathrm{RT}$ (see the fig 4.) which was chemical entity of interest. The same sample was then subjected to LC-MS/MS analysis. The MS spectral data of peak at $10.41 \mathrm{~min}$ gave $[\mathrm{M}+\mathrm{H}]^{+}$ion peak at m/z 271 and MS/MS ion peaks at m/z 253, 243, 215 and 153. Based on the mass and HPLC data it was not possible to characterize the major peak. Semi-preparative HPLC was employed for isolation of major peak of interest.

\section{Figure 4: HPLC Graph with PDA Spectra}

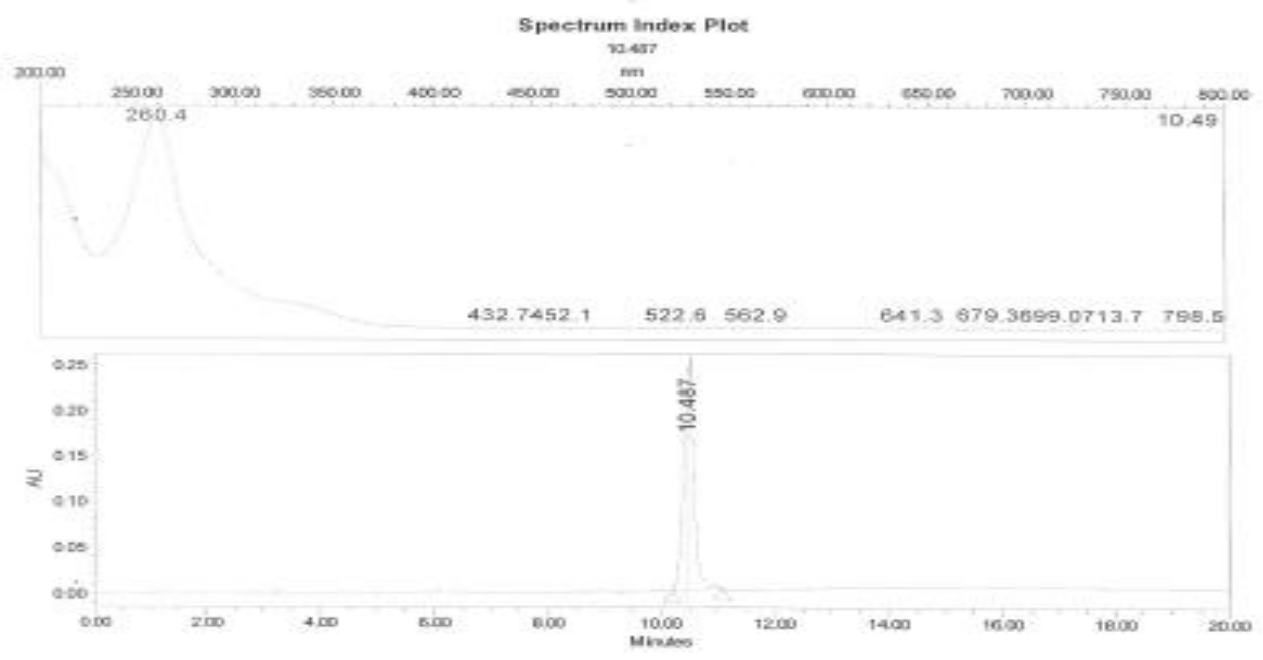

The obtained material was lyophilized and with purity by HPLC greater than $99 \%$. The ${ }^{1} \mathrm{H}$ NMR of isolated material revealed the presence of 7 aromatic protons with 3 exchangeable protons (confirmed by $\mathrm{D}_{2} \mathrm{O}$ exchange). ${ }^{13} \mathrm{C}$ and DEPT-135 NMR spectra data revealed presence of total fifteen carbon atoms with seven methylene and eight quaternary groups.

The proposed structure of 5,7-Dihydroxy-3-(4-hydroxyphenyl)chromen-4-one i.e Genistein was also supported by FTIR analysis. The confirmation of this compound was then carried out by co-injecting the commercially available Genistein reference material.

\section{Reference}

[1]. Enquist L.W., Bradley S.G.(1971) Characterization of deoxyribonucleic acid from Streptomyces venezuelae species. Dev. Ind. Microbiol. 12:225-236.

[2]. Holt, J.H., Kreig, N.R., Sneath, J.J. and Williams, S.T. (1994) In: Bergey's Manual of Determinative Bacteriology, $9^{\text {th }}$ edition, Williams and Wilkins Publication, Baltimore, Maryland, USA.

[3]. Leclerq G, Heuson JC, "Physiological and pharmacological effects of estrogens in breast cancer," Biochim Biophys Acta, 560: $427-55,1979$.

[4]. Mehling, A., Wehmeier, U. F. \& Piepersberg, W. (1995). Nucleotide sequences of streptomycete 16S ribosomal DNA: towards a specific identification system for streptomycetes using PCR. Microbiology 141, 2139-2147.

[5]. Piepersberg, W. 1993. Streptomycetes and corynebacteria, pp. 434-. 468. In: H.-J. Rehm, G. Reed, A. Pu“ hler, and P. Stadler (series eds.), Biotechnology. 2nd edition. Biological fundamentals, vol. 1. Verlag Chemie, Weinheim. 